\title{
Antibiotic Knowledge, Attitude and Practice of Use Among Early Years Medical and Non-medical Students in Tanzania
}

Veronika Berdnikova ${ }^{1},[\mathrm{PhD}]$

ORCID: 0000-0001-6446-972X

Tatiana Lykina ${ }^{2}$, [MD, PhD]

ORCID: 0000-0003-2191-8913

Zanda Bochkaeva ${ }^{3},[\mathrm{PhD}]$

ORCID: 0000-0001-9218-3331

${ }^{1}$ Department of Biomedical Sciences, College of Health Sciences, University of Dodoma, Dodoma, Tanzania

${ }^{2}$ Department of Clinical Immunology, Allergology and Phthisiopulmonology, Kursk State Medical University, Kursk, Russia

${ }^{3}$ Department of Biology, College of Natural and Mathematical Sciences, University of Dodoma, Dodoma, Tanzania

Corresponding author: Zanda Bochkaeva,

Department of Biological Sciences, College of Natural and Mathematical Sciences, University of Dodoma, Dodoma, Tanzania, PO Box 259

e-mail: zanda.bochkaeva@udom.ac.tz

Phone number: +255768126456

\section{we A B T RACT Cen}

Objective: Antimicrobial resistance has been called one of the greatest threats of the century worldwide. Self-treatment with antibiotics impacts the most on antimicrobial resistance. High-income countries have been conscious of the problem for several years and restrict the availability of antibiotics. In Tanzania there is little control of access to antibiotics, and there is an increasing trend of self-medication with antibacterials. The aim of this study is to assess and compare knowledge of antibiotics and experience of their use among Tanzanian medical and non-medical students.

Materials and Methods: The current study was conducted in the largest Tanzanian university, the University of Dodoma. The study was based on a questionnaire survey, which included questions regarding knowledge about and experience of use of antibiotics, and the socioeconomic situation of the respondent.

Results: Medical students were found to be more knowledgeable about antibiotics, but no significant difference in antibiotic use among medical and non-medical respondents was observed. Medical student respondents had a slightly higher percentage of self-treatment experience. Factors associated with self-treatment rates were different: educational for medical students and economic for non-medical. Analysis of antibiotic usage showed Ampicillin, Amoxicillin and others from Penicillin group to be the most popular between both groups. Nevertheless, many students in both groups, confused antibiotics, pain killers and antiallergic drugs.

Conclusion: In general, the data collected confirmed informal observation of a higher prevalence of self-treatment among medical students than non-medical, common antimicrobial resistance illiteracy and inclination to self-medicate with antibiotics regardless of the ailment in both of groups. This dramatically demonstrates the necessity of antibiotic use guidance and control in the country.

Keywords: Antibiotic resistance, medical students, non-medical students, Tanzania

\section{INTRODUCTION}

It is less than one hundred years since the first antibiotic, penicillin, was discovered in 1928, and humanity already faces the problem of antimicrobial resistance (AMR), which poses an ever-increasing challenge [1].

Many studies have shown antibiotic misuse and overuse to be the major driving factors of AMR [2, 3]. In 2001 the World Health Organization (WHO) released Expert Group recommendations for antibiotic use, where they identified and stressed, amongst other things, the importance of population medical awareness and the development of national 
policies, in the campaign to curb inappropriate antibiotic use [4].

The speed of AMR growth in low-income countries is startling! [5]. Tanzania has only recently started to address the problem of AMR, through the discussion of the AMR burden in Tanzania by local and foreign clinical microbiologists, which have emphasized the impact of drug availability and lack of basic knowledge about antibiotics use [6-9].

Centralized control and basic medical education, including improvements of University curricula, should be the first steps to combat AMR, and the Tanzanian Government is working on a national plan to deal with AMR [10].

At present there is no effective state stewardship policy or guidance for antibiotic use in the country. Antimicrobials continue to be available in every small pharmacy without any medical prescription or medical supervision. Moreover, these small local pharmacies are much more accessible to the population than are the much scarcer dispensaries with at least some medical supervision [11]. In these circumstances people rely on their own knowledge about cold and flu treatment and the advice of pharmacy workers [11-12], which results in the overuse of antimicrobials. Health care workers are known to be an antibiotic overuse risk group; even medical students tend to ignore doctor's advice or avoid medical consultation [13]. The current situation in Tanzania is poorly documented and further research is needed to provide the necessary data for policy and stewardship development.

\section{Aim}

The current study investigates and compares the knowledge, attitude and practice of antibiotic use among medical (MD) and non-medical (non-MD) Tanzanian students to find the specific education-associated factors contributing to self-treatment among Tanzanian students.

\section{MATERIALS and METHODS}

\section{Study Design and Study Site}

The study was conducted in May 2017 in the
University of Dodoma (UDOM) in Tanzania. UDOM is the largest University in Tanzania, where students from the whole country study and live on campus altogether.

Identical questionnaires were written in English and distributed to two groups of $2^{\text {nd }}$ year students: medical students (MD) and students of College of Natural and Mathematical Sciences (non-MD). Questionnaires consisted of closed and semi-closed questions, which were divided into three parts: personal experience of antibiotic use, knowledge about antibiotics and general socioeconomic information. Some of questions allowed respondents to choose more than one of the answers provided (for example, symptoms treated by antibiotics). For these questions, the percentage of students, choosing each answer, was counted in every group.

All students were briefed verbally about the study and informed that their answers would be recorded anonymously.

Received data were transferred to Excel spreadsheets to compare results between MD and nonMD groups.

\section{Study Group, Sample Size and Exclusion Criteria}

All second year MD students and a similar number of $2^{\text {nd }}$ year non-MD students were recruited into the study. In total, 370 questionnaires were distributed: 184 to the MD group and 186 to the non$M D$. Fourteen of non-MD questionnaires were returned incomplete and excluded from the study; $184 \mathrm{MD}$ and 172 non-MD answers were analyzed in the study.

\section{Statistical Analysis}

Frequencies and percentages were counted using Microsoft Excel. Statistical analysis was done using MedCalc statistical software. A p-value of less than 0.05 was considered statistically significant.

\section{Ethical Approval}

The Ethical commission of UDOM approved the study. Students were informed, that their data would be analyzed for study anonymously. 


\section{Socioeconomic Characteristics of Groups}

Both study groups showed similar socioeconomic characteristics: most were between 20 and 25 years old, basically males, and around a quarter of respondents were married or had a partner. Some of them had a child, or children. Only $24.5 \%$ (45/184) of MD and $19.2 \%$ (33/172) of non-MD students had a free medical insurance, the remainder bought their own insurance or had none.

Monthly incomes were converted from Tanzanian shillings to US dollars for ease of understanding. Most respondents, 78.8\% (145/184) MD and 71.5\% (123/172) non-MD had a monthly income of less than $120 \$ .49 .5 \%$ (91/184) of MD, and 36.6\% (63/172) of non-MD, reported a monthly income of less than $\$ 70$. All socioeconomic differences between groups were found to be statistically insignificant.

Influence of Medical Education on Antibiotic Self-treatment

Results have shown that non-MD students are slightly more likely to resort to antibiotic self-treatments, $46.2 \%$ (66/143), as against $35.1 \%(59 / 168)$ of MD (Table 1), but the ratio was hardly statistically significant (OR $0.6315,95 \% \mathrm{Cl}: 0.4000$ to 0.9969 , $\mathrm{p}=0.0485$ ).

Interestingly, analysis of self-treatment causes,

Table 1. Experience of antibiotics use ( $\mathrm{n} \%)$. showed, despite none of the students choosing "lack of trust in doctor" as their answer, about half of all respondents believed that they didn't have enough time for a doctor's consultation. Lack of time was the most popular answer among MD students, 59.3\% (35/59), whilst 51.5\% (34/66) of non-MD students replied, that they didn't attend the doctor to save money. Statistically the money saving answer was found to be associated with the absence of medical education (OR 0.2157, 95\% Cl: 0.0956 to $0.4867, p=0.002$ ). It should be noted that some MD students believe they have enough knowledge to make a decision about antibiotics themselves $(13.6 \%, 8 / 59)$. The rest of respondents were unable to identify the reason: $8.5 \%$ of $\mathrm{MD}(5 / 59)$ and $3 \%$ of non-MD (2/66).

When choosing the medicine type, most respondents relied on a previous experience: $76.3 \% \mathrm{MD}$ and $57.6 \%$ non-MD chose this answer. The next most common approach, notably popular among Tanzanian students, was to follow Pharmacist's recommendations: $22 \% \mathrm{MD}$ and $24.2 \%$ non-MD. Notably fewer students chose other options, like "somebody's advice" and "Internet or advertising", from both groups.

\begin{tabular}{|l|c|c|c|c|}
\hline Group & MD (n=184) & Non-MD (n=172) & OR (95\% Cl) & p-value \\
\hline Have you ever taken antibiotics? & $16(8.7 \%)$ & $29(16.9 \%)$ & $0.4696(0.2452$ to 0.8994$)$ & 0.0226 \\
\hline No & $168(91.3 \%)$ & $143(83.1 \%)$ & & \\
Yes & $59(35.1 \%)$ & $66(46.2 \%)$ & $0.6315(0.4000$ to 0.9969$)$ & 0.0485 \\
\hline If "yes", did you have doctor prescription for antibiotics? & $77(53.8 \%)$ & & \\
\hline No & $109(64.9 \%)$ & & \\
Yes & \multicolumn{1}{|l|}{} & & \\
\hline
\end{tabular}

\section{Common Practice of Antibiotic Use}

Generally, students used antibiotics to treat upper respiratory tract infections and fever, as well as diarrhea and skin wounds (Table 2).

All the groups reported the same level of foresight and preparation: about half of the respondents in each group, read all the instructions, and more than a half follow current or previous doctor's recommendations. Nevertheless, about half of MD students, $48.8 \%$, and only $27.3 \%$ of non-MD students usually completed the course (OR 2.5426, $95 \%$ Cl: 1.5790 to $4.0943, p=0.0001)$. The others had stopped taking the drugs, when symptoms disappeared or for other reasons. 
Table 2. Conditions treated by antibiotics ( $\mathrm{n} \%)$.

\begin{tabular}{|l|c|c|}
\hline Group & MD $(\mathrm{n}=168)$ & Non-MD $(\mathrm{n}=143)$ \\
\hline What condition(s) did you treat with antibiotics? & $30(17.9 \%)$ & $2(1.4 \%)$ \\
\hline Runny nose & $17(10.1 \%)$ & $3(2.1 \%)$ \\
Nasal congestion & $58(34.5 \%)$ & $50(35.0 \%)$ \\
Cough & $45(26.8 \%)$ & $14(9.8 \%)$ \\
Sore throat & $53(31.5 \%)$ & $56(39.2 \%)$ \\
Fever & $32(19.0 \%)$ & $31(21.7 \%)$ \\
Aches and pains & $8(4.8 \%)$ & $12(8.4 \%)$ \\
Vomiting & $58(34.5 \%)$ & $25(17.5 \%)$ \\
Diarrhea & $18(10.7 \%)$ & $21(14.7 \%)$ \\
Skin wounds & & \\
\hline
\end{tabular}

\section{Knowledge about Antibiotics}

MD students demonstrated expectedly higher awareness about antibiotic indication. 97.8\% (180/184) of MD, and only $80.9 \%$ (127/157) of nonMD respondents knew that antibiotics can treat bacterial infection (OR 10.63, 95\% Cl: 3.65 to 30.9, $\mathrm{p}<0.0001)$. MD students, $46.2 \%(85 / 184)$, appeared to be significantly more educated about the AMR problem than non-MD students, 19.1\% (30/157), (OR $3.63,95 \% \mathrm{Cl}: 2.22$ to $5.95, \mathrm{p}<0.0001)$.

\section{Trends of Antibiotics}

Students were asked to identify which antibiotics, they had used. The number of possible entries was limited to 5 . In the first instance, it was observed, that around $20 \%$ of drugs named as antibiotics by both MD and non-MD respondents, were not in fact antimicrobials. Typically, this $20 \%$ of misclassified drugs were painkillers and antiallergenic medicines. As at least 3 out of 5 medicines in each questionnaire were antimicrobials, the data was included in the analysis.

Antibiotic trends were predictable. The most popular was Amoxicillin, the next, Metronidazole, and then others such as, Penicillin, Ampicillin, Erythromycin and Ciprofloxacin. No student named any combined medicine e.g. Amoxiclav or Augmentin (Amoxicillin/ Clavulanic acid), but some of them, $6 \%$ (10/168) MD and $1.4 \%(2 / 143)$ non-MD, had experience of using Ampiclox (Ampicillin/Cloxacillin) (Figure 1).

- $\mathrm{MD}=$ non-MD

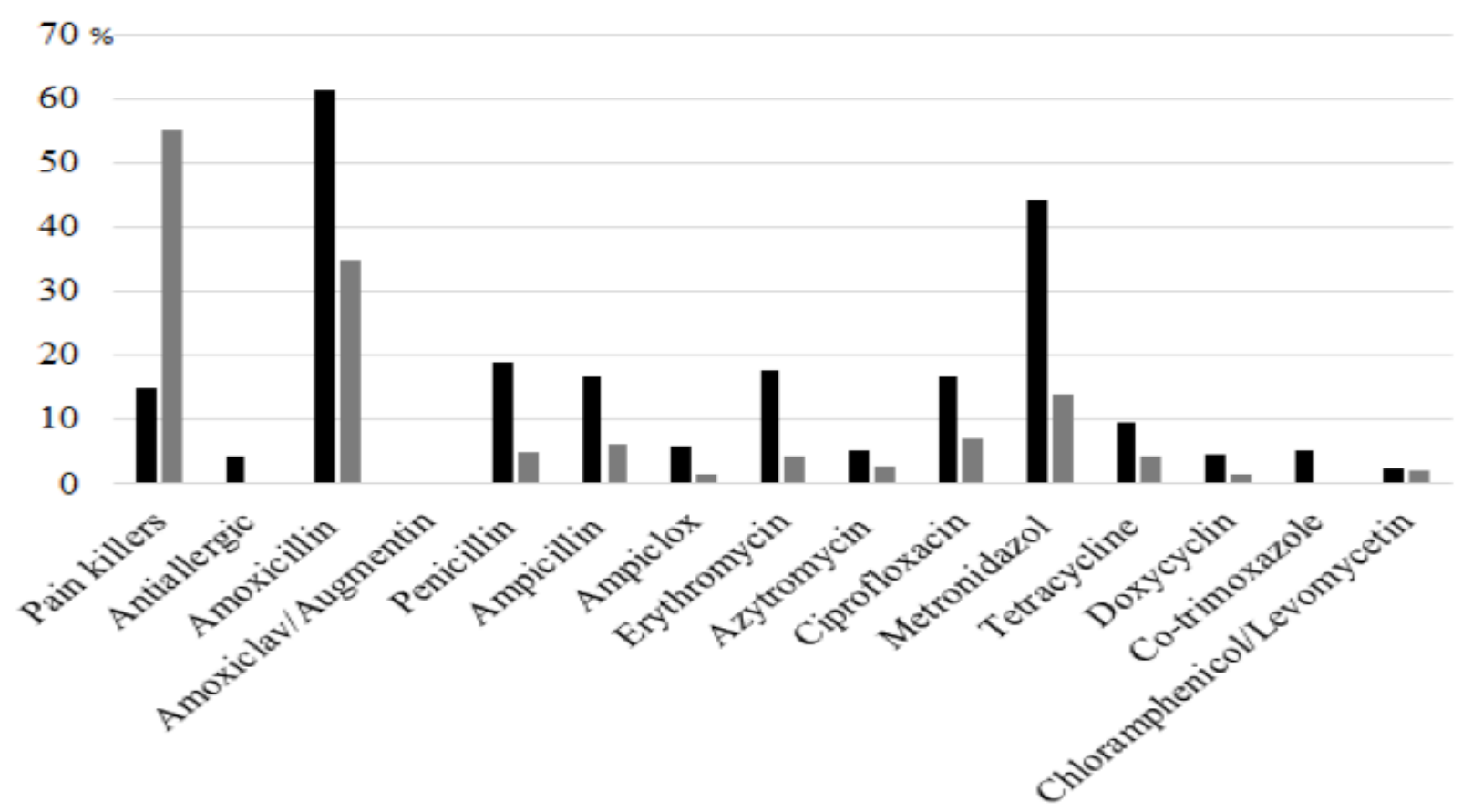

Figure 1. Trends of antibiotics. 


\section{DISCUSSION}

\section{Socio-economic Characteristics}

Individual correlation to the current minimum wage in Tanzania (45\$) was determined [14], to compare the monthly income of students. In summary, students had the expected distribution of incomes for the country's economic situation. Surprisingly, none of the economic or social factors was found to be associated with self-treatment in either of the two groups, though the most popular reason for self-treatment was cost saving among nonMD students.

\section{Self-treatment among Students}

The percentage of students, who have ever used antibiotics, was higher among MD students, reinforcing the opinion, that medical education, completed and not completed, promotes the use of medicines (OR 0.4696, 95\% Cl: 0.2452 to $0.8994, p=0.0226$ ). Most of MD students tend to use antibiotics without prescription, considering that it is easier to rely on their own knowledge rather than to arrange a doctor's consultation, an opinion common among all healthcare workers [13]. This behavior is unwise for the MD student group, who are only in the 2 nd year of medical studies. Our results show that even early years MD students are more likely to use antibiotics without prescription than non-MD.

\section{Comparison of Knowledge and Attitude about Antibiotics among Tanzanian MD and Non-MD Students}

Different factors affected the decision to not visit a doctor before antibiotic treatment in the two studied groups. Medical students understand the importance of a doctor's consultation, but don't have time to go to a health care unit, while non-MD students ignore the professional consultation because of cost. The tendency to save money on doctor's consultations confirms the lack of knowledge among non-MD students in comparison to MD, observed in the section of the data "knowledge about antibiotics": although $91.3 \%$ of non-MD answered, that they know what an antibiotic is, only $80.9 \%$ of them selected the "it's medicine to treat bacterial infection" answer, while the others thought that antibiotics are painkillers, antiviral or anti-allergic drugs. $97.8 \%$ of MD students were sure, that antibiotics are antibacterial drugs.

It is interesting to note that only $55.3 \%(93 / 168)$ of MD and 42\% (60/143) of non-MD students either complete the course of medication or stop taking the drugs after a medical consultation (OR 1.7153, 95\% Cl: 1.0933 to $2.6912, p=0.0189$ ), (Figure 2). These observations reflect the level of medical education and awareness: more than a half of MD students understand the importance of proper course completion while the majority of non-MD students give up treatment for a variety of reasons, either the disappearance of symptoms or running out of drugs. Both of groups showed a disappointingly high percentage of inappropriate use of antibiotics for treating aches, pains and fever and a tendency not to complete the course (Table 2 and Figure 2). 


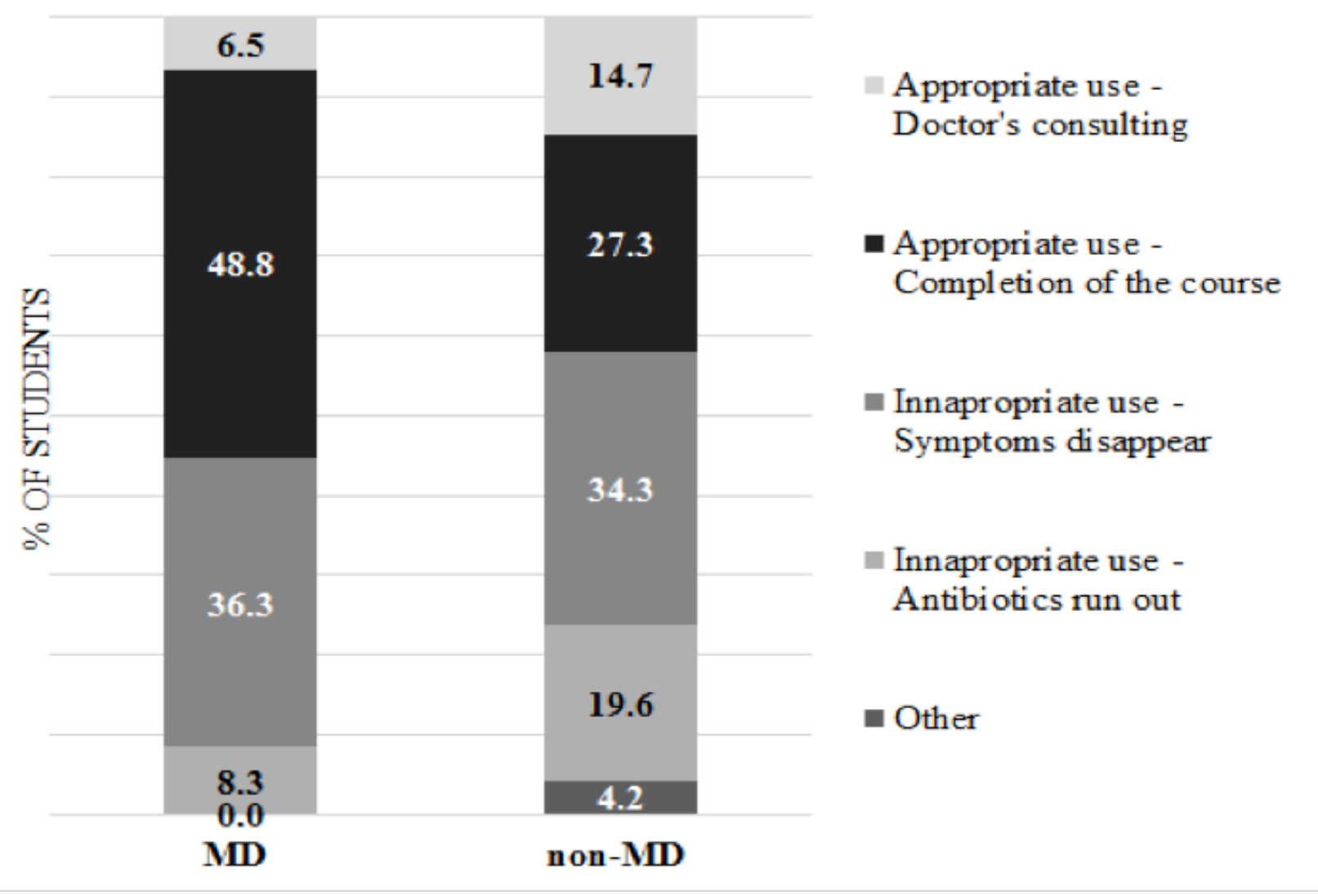

Figure 2. Reasons to stop taking antibiotics among MD and non-MD students.

\section{Trends of Antibiotics in Tanzania}

Trends in types of antibiotics were mostly the same among MD and non-MD students. The most commonly used antibiotics in both groups are those of the penicillin group, especially Amoxicillin, as it is a cheap, broad-spectrum antibiotic, and Ampicillin, which was popular among MD students. Unexpectedly, Tanzanian students defined Penicillin as another popular antibiotic (Figure 1). Unfortunately, timeframes were not defined in the questionnaire, so we couldn't identify when the antibiotic was used: many years ago or recently.

The next most popular group of antibiotics was the Fluoroquinolones. In the context of this observation, it should be noted, that students, living in dormitories have been proven to be a population at risk of methicillin-resistant Staphylococcus aureus infection (MRSA) [15], which is one of the most prevalent causative agents of upper respiratory tract infections, urinary tract infections and sepsis. Quinolones have been shown to be the drivers of MRSA colonization $[16,17]$ and it is known, that in a case of
MRSA infection all beta-lactam antibiotics, including Penicillin, are ineffective. To avoid the aggravation of MRSA outbreak, culturing and antibiotic sensitivity tests are essential before selecting appropriate antibiotics, especially in campuses.

Combined antibiotics, like Amoxiclav and Augmentin, being the most expensive among the penicillin group, were not popular among students. At the same time Metronidazole was found to be the second (after Ampicillin) most used antibiotic among MD students, which is still the drug of choice for treatment of anaerobic infections [18], and some sexually transmitted infections.

\section{CONAUSION}

The prevalence of self-treatment between both groups was high. The comparison of MD and nonMD students showed significant differences in knowledge and practice regarding antimicrobial use. These observations demonstrate that, feeling that they are more educated about antibiotics and AMR even at only the 2 nd year of medical education, MD students show the typical for health care 
workers behavior - antibiotic overuse.

Amoxicillin has been shown to be the most popular antibiotic, whilst Cephalosporins, one of the most popular antibiotic groups in Europe, are unknown among Tanzanian students.

Despite economic reasons being identified as the determining factor for self-treatment by non-medical students, the statistical analysis didn't show any socioeconomic factor associated to antimicrobial self-treatment. Though minor differences in details, rationale and education were found, all students showed a high degree of inappropriate use of antibiotics, demonstrating the importance of Governmental regulations regarding availability by doctor's prescription only, to avoid further development of the burden of AMR.

\section{ACKNOWLEDGEMENTS}

Authors wish to acknowledge Ned Kemp for revision and correction of English in the article.

\section{CONFUCT Of INTEREST}

Each author declares that he or she has no commercial associations (e.g. consultancies, stock ownership, equity interest, patent/licensing arrangement etc.) that might pose a conflict of interest in connection with the submitted article.

\section{Author's Contribution}

All authors participated in collecting data equally. VB summarized and analyzed the data. TL participated in review of the draft. ZB designed the study, interpreted the data and drafted the manuscript. All authors reviewed and approved the manuscript.

\section{Limitations of The Study}

This survey was restricted to $2^{\text {nd }}$ year students only. The same survey administered to final year MD and non-MD students is recommended in order to understand the influence of completed professional education on attitude and use of antibiotics in comparison to early professional education. 
[1] Antimicrobial resistance: Global Report on Surveillance. Geneva, Switzerland; World Health Organization, 2014: 257.

[2] Jorgensen PS, Wernli D, Carroll SP, et al. Use antimicrobials wisely. Nature 2016; 537(7619): 159-61.

[3] Castro-Sanchez E, Moore LS, Husson F, et al. What are the factors driving antimicrobial resistance? Perspectives from a public event in London, England. BMC Infect Dis. 2016; 16(1): 465.

[4] Antibiotic resistance: synthesis of recommendations by expert policy groups. Alliance for the Prudent Use of Antibiotics. World Health Organization 2001. https://apps. who.int/iris/handle/10665/66895 (accessed September 2017).

[5] Pehrsson EC, Tsukayama P, Patel S, et al. Interconnected microbiomes and resistomes in low-income human habitats. Nature. 2016; 533(7602): 212-6.

[6] Buguzi S. Tanzania: when bugs fight back - antibiotic resistance in Tanzania. The Citizen 2016. http://allafrica.com/ stories/201607181218.html (accessed September 2017).

[7] Buguzi S. 12 bacteria resistant to antibiotics identified. The Citizen 2017. http://www.thecitizen.co.tz/News/12bacteria-resistant-to-antibiotics-identified/18403403837520-uodccsz/index.html (accessed September 2017).

[8] The use of antibiotics need to be regulated. The Citizen 2017. http://www.thecitizen.co.tz/oped/THE-USE-OFantibiotics-NEEDS-TO-BE-REGULATED/1840568-408315229w4ue/index.html (accessed September 2017).

[9] Lugano $W$. This is the right time to fight antibiotic resistance. The Citizen 2018. https://www.thecitizen.co.tz/ magazine/This-is-the-right-time-to-fight-antibioticresistance/1840564-4282972-vm33dv/index.html (accessed June 2019).

[10] Buguzi S. Govt acts on growing antibiotic resistance. The
Citizen 2017. http://www.thecitizen.co.tz/News/Govtacts-on-growing-antibiotic-resistance/1840340-381337210c7p05z/index.html (accessed September 2017).

[11] Embrey M, Vialle-Valentin C, Dillip A, et al. Understanding the role of accredited drug dispensing outlets in Tanzania's health system. PLoS One. 2016; 11(11): e0164332.

[12] Nsimba SE. Assessing the performance, practices and roles of drug sellers/dispensers and mothers'/guardians' behavior for common childhood conditions in Kibaha district, Tanzania. Trop Doct. 2007; 37(4): 197-201.

[13] Struzycka I, Mazinska B, Bachanek T, et al. Knowledge of antibiotics and antimicrobial resistance amongst final tear dental students of Polish medical schools - A cross-sectional study. Eur J Dent Educ. 2019; 23(3): 295-303.

[14] Minimum Wages in Tanzania with effect from 01-07-2013. Last update: 19-08-2016. https://wageindicator.org/main/ salary/minimum-wage/tanzania (accessed January 2019).

[15] Centers for disease control and prevention. General information about MRSA in the community. 2016. https:// www.cdc.gov/mrsa/community/index.html (accessed January 2019).

[16] Tacconelli E, De Angelis G, Cataldo MA, et al. Does antibiotic exposure increase the risk of methicillin-resistant Staphylococcus aureus (MRSA) isolation? A systematic review and meta-analysis. J Antimicrob Chemother. 2008; 61(1): 26-38.

[17] Muto CA, Jernigan JA, Ostrowsky BE, et al. SHEA guideline for preventing nosocomial transmission of multidrug-resistant strains of Staphylococcus aureus and enterococcus. Infect Control Hosp Epidemiol. 2003; 24(5): 362-86.

[18] Lofmark S, Edlung C, Nord CE. Metronidazole is still the drug of choice for treatment of anaerobic infections. Clin Infect Dis. 2010; 50 (Suppl 1): S16-23. 